\title{
FINANÇAS PESSOAIS E EDUCAÇÃO FINANCEIRA: O PERFIL DOS SERVIDORES PÚBLICOS DE UM MUNÍCIPIO DO CENTRO-OESTE BRASILEIRO
}

\author{
Rogério da Silva ${ }^{1}$, Arilda Teixeira ${ }^{2}$, Aziz Xavier Beiruth ${ }^{3}$
}

\begin{abstract}
RESUMO
A educação financeira tem sido tema de grandes discussões devido às crises econômicas que se viveu nos últimos anos. Sua definição e seus impactos têm sido temas de diversos estudos. O objetivo deste trabalho foi identificar o perfil dos servidores públicos, de um município do centro-oeste brasileiro, diante do significado da expressão "educação financeira". Realizou-se uma pesquisa quantitativa descritiva no município de Tangará da Serra (MT), com 800 servidores municipais efetivos entre os dias 16 a 23 de setembro de 2015. Os resultados sugerem que os servidores, na definição do perfil geral relacionados à educação financeira, apresentam baixo conhecimento sobre o endividamento e renda, fato este bom, pois estes dois constructos, são analisados - quanto menor melhor. Apresentam um nível satisfatório de educação financeira assim como conhecimento sobre juros e planejamento de gastos.
\end{abstract}

Palavras-chave: Educação financeira. Finanças pessoais. Servidores públicos.

\section{PERSONAL FINANCE AND FINANCIAL EDUCATION: THE PROFILE OF SERVANTS PUBLIC OF A MUNICIPALITY OF BRAZILIAN MIDWESTERN}

\begin{abstract}
Financial education has been the subject of much discussion due to the economic crisis that lived in recent years. Its definition and its impacts have been subjects of several studies. The objective of this study was to identify the profile of civil servants, a city in the midwestern Brazil, on the meaning of "financial education". We conducted a descriptive quantitative research in the city of Tangará da Serra (MT), with 800 effective municipal employees from 16 to 23 September 2015. The results suggest that the servers in defining the general profile related to financial education, They have low knowledge on debt and income, and this was good, because these two constructs are analyzed - the lower the better. They have a satisfactory level of financial education as well as knowledge of interest and planning expenses.
\end{abstract}

Key words: Financial Education. Personal finances. Public servants.

\section{INTRODUÇÃO}

Nota-se um interesse maior das pessoas na gestão das suas próprias vidas financeiras. Várias causas podem ser identificadas, incluindo uma população urbana crescente, níveis de escolaridade maior, um maior número de instrumentos financeiros disponíveis para investidores individuais e, talvez o mais importante: a consciência da limitada capacidade dos

\footnotetext{
${ }_{2}^{1}$ Fucape Business School

${ }^{2}$ Fucape Business School

${ }^{3}$ Fucape Business School

Volume 5, Número 10

Jul./Dez. 2016

Revista UNEMAT de Contabilidade

ISSN: 2316-8072
} 
governos de garantir às pessoas um futuro, individualmente, por meio de seus planos de assistência social (PEREIRA et al., 2010. Tradução livre).

No Brasil, em 2011, foi criada, através do Decreto Federal 7.397/2010, a Estratégia Nacional de Educação Financeira - ENEF, uma mobilização multissetorial em torno da promoção de ações de educação financeira no Brasil, com o objetivo de contribuir para o fortalecimento da cidadania ao fornecer e apoiar ações que ajudam a população a tomar decisões financeiras autônomas e conscientes.

No mundo, o tema educação financeira é desenvolvido por meio da Organização para Cooperação e Desenvolvimento Econômico - OECD (sigla em inglês - Organization for Economic Co-operation and Development), que conceitua a alfabetização financeira como uma combinação de consciência, conhecimento, habilidade, atitude e comportamentos necessários para a tomada das decisões financeiras, visando alcançar o bem-estar financeiro individual. (OECD, 2012).

Para tal finalidade, neste artigo, utilizou-se como conceito de educação financeira, a definida por Reumond:

Educação financeira é a medida do grau em que um indivíduo entende os principais conceitos financeiros e possui habilidade e confiança para administrar, de forma apropriada, suas finanças pessoais, por médio de decisões de curto prazo e planejamento financeiro de longo prazo, em meio aos eventos que ocorrem em sua vida e às mudanças de condições econômicas (REUMOND, 2010, p. 284).

Com isso, este artigo levantou a seguinte questão de pesquisa: Qual o perfil dos servidores públicos de Tangará da Serra (MT) quanto ao nível de "educação financeira"?

Para responder esta questão de pesquisa o objetivo deste trabalho foi identificar a o perfil dos servidores públicos de um município do centro-oeste brasileiro diante do significado da expressão "educação financeira".

A preferência pelo município de Tangará da Serra - MT se deu, pois de acordo com o site do IBGE a renda média per capita de Tangará da Serra cresceu 108,66\% nas últimas duas décadas, passando de $\mathrm{R} \$ 405,73$ em 1991 para $\mathrm{R} \$ 656,60$ em 2000 e $\mathrm{R} \$ 846,59$ em 2010. A taxa média anual de crescimento foi de $61,83 \%$ no primeiro período e $28,94 \%$ no segundo. 


\title{
2 REFERENCIAL TEÓRICO
}

\subsection{FINANÇAS PESSOAIS}

Tão importante quanto ter uma atividade visando adquirir uma estabilidade financeira é desenvolver o hábito e a cultura de organizá-la. É fundamental que o ser humano, além de conquistar uma boa remuneração, consiga mantê-la. Para isso, torna-se imprescindível que o mesmo desenvolva o controle de suas finanças pessoais (GOMES; SORATO, 2010).

A utilização do estudo das finanças vai muito além do uso nas empresas. A área de finanças abrange tanto a administração de negócios, quanto a administração dos recursos pessoais. As Finanças estão presentes diariamente na vida das pessoas (LEAL; NASCIMENTO, 2008).

Nesse sentido:

\begin{abstract}
Finanças comportamentais tentam colaborar para o entendimento da mente do investidor e para seu comportamento irracional. Desde a crise iniciada em 2008, ficou claro que os economistas haviam simplificado demais os fatos ao julgar que as pessoas (emocionais, contraditórias e medrosas) agiam de forma perfeitamente racional no momento da tomada de decisões financeiras. O comportamento das pessoas é muito mais complexo que os modelos econômicos e financeiros podem supor. Esses modelos são úteis, mas não têm a capacidade de explicar tudo o que ocorre nos mercados. (SANTOS; BARROS; 2011).
\end{abstract}

De acordo com Matsumoto et al. (2013, p. 4): “O tema finanças pessoais trata de como o indivíduo ou família administra a renda. A todo o momento o indivíduo tem que tomar decisões financeiras e essas terão impacto na vida pessoal”.

O tema Finanças Pessoais é atual e aborda o comportamento e conceitos financeiros das pessoas em lidar com dinheiro e como se planejar financeiramente, por exemplo, no financiamento, orçamento doméstico, cálculo de investimento, gerenciamento de contacorrente, plano de aposentadoria, acompanhamento de patrimônio e acompanhamento de gastos como tarefas relacionadas com finanças pessoais. (LEAL; NASCIMENTO, 2008).

A capacidade de entender e administrar as finanças pessoais são uma habilidade de extrema importância na vida do ser humano, se os indivíduos não são capazes de entender desvios do sistema financeiro, não estão apitos a administrar de forma efetiva suas finanças pessoais (DONADIO, 2014).

Obter êxito na gestão das finanças pessoais não está relacionado unicamente ao nível de recursos financeiros acumulados pelo indivíduo durante a vida, mas a capacidade de planejar a disponibilidade destes, para a realização de projetos pessoais e familiares (SAITO, 2014). 


\subsection{EDUCAÇÃO FINANCEIRA}

A educação financeira é um conjunto de técnicas que proporciona um comportamento e modo de pensar que ajuda desde o saneamento de dívidas até um possível enriquecimento, por meio do conhecimento da matemática e termos financeiros que auxiliam as tomadas de decisões (OLIVEIRA; KASPCZAK, 2013).

Para Worthington (2006, p. 59), o conceito de educação financeira abrange a compreensão do contexto econômico e do modo pelo qual as decisões das famílias são afetadas pelas condições e pelas circunstâncias econômicas mais amplas. Para outros, porém, o conceito está focado estritamente na gestão financeira básica, ou seja, na necessidade de compreensão de conceitos relacionados ao orçamento, à poupança, ao investimento e aos seguros. (Tradução livre).

A educação financeira mostra diversas ferramentas para que as pessoas tenham uma vida financeira mais saudável, ou seja, uma vida sem dívidas e imprevistos. Outro propósito importante é a criação da consciência de poupar, isto é, a formação de um acúmulo de capital. Todavia, deixar o dinheiro debaixo do colchão não é o mais recomendável, uma vez que ele desvalorizará com a inflação, entre outros riscos (OLIVEIRA; KASPCZAK, 2013).

A educação financeira de acordo com Oliveira e Kaspczak (2013) está relacionada com o planejamento financeiro pessoal, é um plano em que as pessoas elaboram de acordo com seus valores, buscando seus objetivos, de forma a não comprometer a estabilidade financeira familiar.

Conforme Borges (2014) objetivo real da educação financeira é criar uma mentalidade adequada e saudável em relação ao bom uso do dinheiro na aquisição de bens e serviços, e auxiliar decisões de investimentos nas aplicações financeiras.

\subsection{OPÇÕES DE INVESTIMENTO}

De acordo com Santos e Barros (2011), no mercado financeiro e de capitais existe uma variedade de produtos e serviços à disposição dos investidores. $\mathrm{O}$ processo de seleção de investimento deveria ser baseado a partir de uma análise detalhada e igualmente ponderada de todas as informações que contribuem para a identificação dos respectivos custos de oportunidade. Essa condição propõe a existência de investidores dotados de conhecimentos técnicos e de uma boa dose de bom senso em suas tomadas de decisões. Rover et al. (2009) destaca que em vários problemas de decisão, percebe-se uma diferença entre o comportamento observado e as decisões recomendáveis. 
Os principais investimentos realizados relacionados às finanças pessoais são: Caderneta de Poupança, Certificados de Depósito Bancário, Fundos de Investimentos e Mercados de Ações (OLIVEIRA; KASPCZAK, 2013).

Conforme Leal e Nascimento (2008), “a caderneta de poupança é um investimento tradicional, conservador e muito popular entre investidores de menor renda. Quase todos os bancos comerciais possuem esse tipo de investimento".

De acordo Oliveira e Kaspczak (2013):

Os certificados de depósito bancário (CDB) como são conhecidos, são utilizados pelos bancos como forma de captação de recursos, estes certificados são emitidos com o nome de uma determinada pessoa e vendidos ao público em geral e podem ser negociados a qualquer momento dentro do prazo contratado, com uma taxa bruta e sem tributação e inflação. Quando negociados em prazo menor que o previsto sofre com a incidência dos impostos.

A Comissão de Valores Mobiliários (2014) define "fundo de investimento é uma modalidade de investimento coletivo. É uma estrutura formal que reúne recursos financeiros de diversos investidores, para investimento conjunto".

\section{Conforme Hoji:}

As ações são investimentos de renda variável, isto é, seu resultado financeiro pode ser positivo ou negativo na data de sua realização (venda) em função da variação do preço deste título. Um investimento de renda variável pode proporcionar um retorno financeiro maior no longo prazo (HOJI, 2007, p. 39).

A falta de conhecimento financeiro leva ao endividamento das pessoas, neste aspecto Fernandes e Candido (2014) nos relata "o Brasil ainda possui uma perspectiva otimista quanto ao crescimento econômico, porém existem previsões que já apontam a fadiga desse sistema, e como consequência o seu efeito colateral, o endividamento".

Flores e Vieira ainda ressaltam que:

Nesse cenário, a facilidade de acesso ao crédito é um dos aspectos que diferenciam o funcionário público dos trabalhadores de outras instituições. Para o funcionário público, é muito mais fácil e, em vários produtos, ainda mais barato, obter crédito. Tal fenômeno ocorre, principalmente, pelo fato de que, para as instituições ofertadoras de crédito, emprego público é sinônimo de renda garantida, implicando em menor risco. [...] Se este comportamento conservador prevalecer também em suas decisões de consumo, este grupo deve apresentar uma menor propensão ao endividamento. (FLORES; VIEIRA, 2013).

Para Claudino et al. (2009) "o endividamento pode ser acompanhado pelo descumprimento do compromisso assumido com outrem, surgindo assim à inadimplência, ou seja, o não pagamento pontual dos compromissos financeiros por parte do devedor". 
O endividamento deve ser visto com muita preocupação, percebido também de que maneira os indivíduos que possuem estabilidade financeira têm se comportado diante desse cenário, os estudos de Slomp (2008), o aumento do crédito e incentivo à compra têm resultado em alto nível de endividamento, gerando um problema de ordem social, da chamada "sociedade do consumo".

\subsection{ATITUDE FINANCEIRA}

De acordo com Cerbasi (2012) "as boas práticas de educação financeira devem induzir a escolhas equilibradas. Isso se faz combinando referências matemáticas com práticas ambientais, sociais, filosóficas e éticas".

As atitudes financeiras estão relacionadas ao planejamento das finanças pessoais, neste sentido, Macedo Junior (2007) estabelece que o planejamento financeiro é o processo de gerenciar seu dinheiro, para atingir a satisfação pessoal.

Para eficácia do planejamento financeiro faz se necessário a utilização de planilhas financeiras, fluxo de caixa para identificar os gastos necessários e eliminar os gastos excedidos sobre a renda obtida, como também é necessário o entendimento sobre a relação entre o dinheiro e as variáveis que influenciam o comportamento das pessoas, como poder e luxo (BORGES, 2013).

\subsection{COMPORTAMENTO FINANCEIRO}

De acordo com estudos realizados pela a OECD (2013) o comportamento financeiro está relacionado maneira em que uma pessoa se comporta, e como este comportamento terá um impacto significativo sobre o seu bem-estar financeiro.

O comportamento financeiro está relacionado a como as pessoas pensam antes de fazerem uma compra, pagarem contas em tempo e orçamento realizados, poupança e empréstimos para fazer face às despesas (OECD, 2013).

Neste sentido Donadio (2014) relata que além do conhecimento econômico, outros fatores podem determinar o bom ou mau comportamento financeiro e, consequentemente, o maior ou menor grau de sucesso.

\subsection{CONHECIMENTO FINANCEIRO}

O Conhecimento financeiro é a capacidade adquirida ao longo dos anos de vida, para gerir receitas, despesas e poupança, de forma eficaz (POTRICH et al., 2014). 
O conhecimento financeiro está relacionado a questões sobre inflação, taxa de juros, valor do dinheiro no tempo, risco, retorno, diversificação, mercado de ações, crédito e títulos públicos (POTRICH et al., 2014).

Neste sentido Potrich et al. (2014) "o conhecimento financeiro é o foco principal da educação financeira, enquanto que a alfabetização financeira engloba além do conhecimento, o comportamento e a atitude financeira dos indivíduos".

\section{METODOLOGIA}

Este artigo buscou identificar o perfil dos servidores públicos municipais de Tangará da Serra - MT diante o significado da expressão "educação financeira". Nesse sentido, buscou identificar o conceito de "educação financeira" de um grupo específico da sociedade brasileira e caracteriza-lo diante dos constructos propostos - atitude financeira, comportamento financeiro e conhecimento financeiro.

A pesquisa foi desenvolvida no município de Tangará Serra - MT que possui uma população estimada de 83.431 habitantes, com Índice de Desenvolvimento Humano Municipal (IDHM) em 2010 de 0,729 e um Produto Interno Bruto (PIB) em 2012 de R\$ 905.873,00 (IBGE, 2015). Possuía de acordo do sítio do Ministério da Previdência, em março de 2015, 1.516 funcionários públicos efetivos.

O universo estudado foi composto dos servidores municipais distribuídos nos seguintes órgãos públicos: 17 servidores da Câmara Municipal; 01 servidor do Instituto Municipal de Previdência Social (SERRAPREV); 65 servidores do Serviço Autônomo Municipal de Água e Esgoto (SAMAE); 1.433 servidores da Prefeitura Municipal.

A metodologia utilizada quanto aos objetivos da pesquisa foi uma pesquisa quantitativa descritiva, de acordo com Ferrão (2003, p. 80), “a pesquisa descritiva: promove estudo, análise, registro e interpretação dos fatos do mundo físico, sem a interferência do pesquisador. [...]".

A coleta de dados foi feita através de aplicação de questionários estruturados com escala tipo Likert, por este método há condições de conhecer, através de questões respondidas, informações sobre a situação, expectativas, interesses, motivações, características (GIL, 1999).

O questionário da pesquisa foi elaborado de acordo com o Quadro 1:

\begin{tabular}{|c|c|c|}
\hline TEMA & Variáveis / Componentes & Referências \\
\hline \multirow{2}{*}{$\begin{array}{c}\text { Perfil dos respondentes considerando variáveis } \\
\text { demográficas e culturais }\end{array}$} & Sexo & \multirow{2}{*}{ Elaborado pelo Autor } \\
\cline { 2 - 2 } & Idade & \\
\cline { 2 - 2 } & Estado Civil & \\
\hline
\end{tabular}




\begin{tabular}{|c|c|c|}
\hline & Números de Filhos & \\
\hline & Escolaridade & \\
\hline & Renda Mensal & \\
\hline Atitude Financeira & $\begin{array}{c}06 \text { questões: } \\
\mathrm{Q} 7,8,9,23,28,30 .\end{array}$ & \\
\hline Comportamento Financeiro & $\begin{array}{c}08 \text { questões: } \\
\text { Q } 12,13,18,19,20,21, \\
24,27 .\end{array}$ & $\begin{array}{l}\text { Elaborado a partir dos estudos } \\
\text { Claudino (2009); } \\
\text { Flores et al. (2013); }\end{array}$ \\
\hline Conhecimento Financeiro & $\begin{array}{c}10 \text { questões: } \\
\mathrm{Q} 10,11,14,15 ; 16,17, \\
22,25,26,29 .\end{array}$ & Vieira et al. (2011). \\
\hline
\end{tabular}

Quadro 1: Síntese do instrumento de coleta de dados

Fonte: Dados da pesquisa. Elaborado pelo autor.

Para validação dos 3 constructos, atitude Financeira, Comportamento financeiro e conhecimento financeiro, foram realizados a analise fatorial exploratória, e o teste de Alpha Cronbach, utilizando o software estatístico IBM® SPSS Statistics 20.0.

Segundo Hair et al. (2005, p.111), "a ideia de consistência interna é que os itens ou indicadores individuais da escala devem medir o mesmo construto e assim ser altamente intercorrelacionados". O valor do Alpha de Cronbach pode variar de 0 a 1, porém, os valores de 0,60 a 0,70 são considerados os mínimos aceitáveis.

\section{RESULTADOS DA PESQUISA QUANTITATIVA}

A pesquisa foi realizada nos dias 16 a 21 de setembro de 2015 nas dependências do centro político-administrativo, escolas, unidades de saúde, autarquia e câmara de vereadores de Tangará Serra - MT.

Foram distribuídos 1.500 questionários, dos quais foram respondidos $900 \mathrm{e}$ descartados 100, por não conterem todas as respostas e/ou haver respostas erradas. Nesse sentido, a amostra pesquisada corresponde a 800 servidores que representam $53 \%$ do universo estudado.

A estatística descritiva do perfil da amostra está apresentada na Tabela 1.

Tabela 1 - Distribuição de Frequência das características sócio demográficas

\begin{tabular}{llcc}
\hline Variável & & n & \%n \\
\hline \multirow{2}{*}{ Gênero } & Masculino & 243 & $30 \%$ \\
& Feminino & 557 & $70 \%$ \\
\hline \multirow{2}{*}{ Faixa de Idade } & 18 a 28 anos & 104 & $13 \%$ \\
& 29 a 39 anos & 278 & $35 \%$ \\
& 40 a 50 anos & 269 & $34 \%$ \\
& 50 anos ou mais & 149 & $19 \%$ \\
\hline \multirow{2}{*}{ Estado Civil } & Solteiro (a) & 162 & $20 \%$ \\
& Casado (a) & 446 & $56 \%$ \\
& Viúvo (a) & 8 & $1 \%$ \\
& Outros & 184 & $23 \%$ \\
\hline Volume 5, Número 10 & & & \\
Jul./Dez. 2016 & & Revista UNEMAT de Contabilidade \\
& & ISSN: 2316-8072
\end{tabular}




\begin{tabular}{|c|c|c|c|}
\hline \multirow{7}{*}{ Nível de Escolaridade } & Ensino Fundamental Incompleto & 10 & $1 \%$ \\
\hline & Ensino Fundamental completo & 39 & $5 \%$ \\
\hline & Ensino Médio Incompleto & 40 & $5 \%$ \\
\hline & Ensino Médio completo & 100 & $13 \%$ \\
\hline & Ensino Superior Incompleto & 147 & $18 \%$ \\
\hline & Ensino Superior completo & 234 & $29 \%$ \\
\hline & Pós-Graduação & 230 & $29 \%$ \\
\hline \multirow{7}{*}{ Renda Mensal } & Até R\$ $1.000,00$ & 22 & $3 \%$ \\
\hline & $\mathrm{R} \$ 1.000,01$ a $\mathrm{R} \$ 2.000,00$ & 196 & $25 \%$ \\
\hline & $\mathrm{R} \$ 2.000,01$ a $\mathrm{R} \$ 3.000,00$ & 206 & $26 \%$ \\
\hline & $\mathrm{R} \$ 3.000,01$ a $\mathrm{R} \$ 4.000,00$ & 152 & $19 \%$ \\
\hline & $\mathrm{R} \$ 4.000,01$ a $\mathrm{R} \$ 5.000,00$ & 115 & $14 \%$ \\
\hline & $\mathrm{R} \$ 5.000,01$ a $\mathrm{R} \$ 6.000,01$ & 57 & $7 \%$ \\
\hline & $\mathrm{R} \$ 6.000,01$ acima & 52 & $7 \%$ \\
\hline \multirow{5}{*}{ Você mora em: } & Casa própria que está quitada (está paga) & 448 & $56 \%$ \\
\hline & Casa financiada (paga prestações do financiamento) & 176 & $22 \%$ \\
\hline & Casa alugada & 88 & $11 \%$ \\
\hline & Com familiares para não ter despesa com moradia & 66 & $8 \%$ \\
\hline & Com familiares para ajudar nas despesas & 22 & $3 \%$ \\
\hline \multirow{6}{*}{$\begin{array}{l}\text { Quando você pensa em } \\
\text { dinheiro você pensa em: }\end{array}$} & Segurança & 304 & $38 \%$ \\
\hline & Aparência & 6 & $1 \%$ \\
\hline & Gastos & 60 & $8 \%$ \\
\hline & Sobrevivência & 408 & $51 \%$ \\
\hline & Alegria & 14 & $2 \%$ \\
\hline & Juros & 8 & $1 \%$ \\
\hline Total & & 800 & $100 \%$ \\
\hline
\end{tabular}

Fonte: Dados da pesquisa. Elaborado pelo autor.

A Tabela 1 permitiu avaliar o perfil dos respondentes quanto aos dados sócios demográficos, a qual predominaram as seguintes características: sexo feminino com $70 \%$; em relação faixa de idade, $35 \%$ dos respondentes têm entre 29 a 39 anos e $34 \%$ têm entre 40 e 50 anos; no estado civil, mais de $50 \%$ dos entrevistados são casados; quanto ao nível de escolaridade, $58 \%$ têm no mínimo o ensino superior; e em relação à faixa de renda, $70 \%$ têm renda entre $\mathrm{R} \$ 1.000,00$ à $\mathrm{R} \$ 4.000,0$ reais; $78 \%$ possui casa própria ou financiada; e por fim, na preposição "quando você pensa em dinheiro você pensa em:" para $79 \%$ dos servidores o dinheiro está relacionado à segurança ou sobrevivência.

Com relação ao número de filhos, a maior frequência foi a de 2 filhos, correspondente a 30,5\%; seguindo de um 1 filho na porcentagem de $22,8 \%$ os demais dados estão apresentados abaixo:

Tabela 02 - Estatística descritiva: números de filhos

\begin{tabular}{cccc}
\hline Números de Filhos & n & \%n \\
\hline 0 & 172 & 21,5 \\
1 & 182 & 22,8 \\
2 & 244 & 30,5 \\
3 & 113 & 14,1 \\
\hline 4 ou mais & 89 & 11,1 \\
\hline TOTAL & $\mathbf{8 0 0}$ & $\mathbf{1 0 0}$ \\
\hline \hline
\end{tabular}


Fonte: Dados da pesquisa. Elaborado pelo autor.

Passa-se agora a interpretar o padrão de consumo da amostra. Verificou-se que $56 \%$ dos entrevistados residiam em casa própria; e que quando o assunto é dinheiro a sua maior preocupação está ligada à sobrevivência $(51 \%)$ e à segurança - Tabela 1 .

Dentre os bens essenciais, a maior preocupação está com a saúde (28,5\%), seguido de moradia (26\%) e alimentação (24\%). Cabe destacar que a preocupação em poupar ocupa apenas $2,5 \%$ na ordem de importância dos entrevistados - Tabela 3.

Tabela 3 - Estatística descritiva: ordem de importância dos bens

\begin{tabular}{lr} 
Coloque, em ordem decrescente de importância (essencialidade), para você, os seguintes & n \\
bens: & $28,5 \%$ \\
Saúde & $26 \%$ \\
Moradia & $24 \%$ \\
Alimentação & $16,5 \%$ \\
Educação & $2,5 \%$ \\
Poupança & $0,8 \%$ \\
Lazer & $0,7 \%$ \\
Transporte & $0,5 \%$ \\
Cultura & $\mathbf{1 0 0 \%}$ \\
\hline TOTAL & $0,5 \%$ \\
\hline
\end{tabular}

Fonte: Dados da pesquisa. Elaborado pelo autor.

\subsection{ESTATÍSTICA DESCRITIVA DOS CONSTRUCTOS}

Em função do objetivo da presente pesquisa, os respondentes foram questionados referentes aos constructos "Atitude Financeira", "Comportamento Financeiro" e “Conhecimento Financeiro", o primeiro foi constituído por meio de 3 perguntas, e o segundo, por meio de 9 perguntas, e o terceiro constructo sendo representado por 10 perguntas. $\mathrm{O}$ questionário foi estruturado para que se pudesse captar com mais detalhes os aspectos que envolvem a concepção de finanças pessoais.

As perguntas de 10 a 30 foram desenvolvidas através da escala tipo Likert, com 5 proposições: DT - discordo totalmente; DP - discordo parcialmente; I - indiferente; C concordo; CT - concordo totalmente, para captar a percepção dos entrevistados em relação aos conhecimentos de educação financeira, endividamento e investimentos - ANEXO.

A Tabela 4 contém as médias e desvios padrões das perguntas referentes constructos. A consistência internamente dos constructos foi avaliada por meio do cálculo Alpha de Cronbach. Os valores variam entre 0 e 1 , medidas mais altas sugerem maior coerência entre os indicadores (HAIR et al., 2005).

Analisando a Tabela 4, no geral, notou-se que as perguntas que se mostravam razoavelmente importante, com médias próximas ou acima de 4 foram: P12 (4,19), P27 
$(4,33)$, P10 $(4,19)$ e P22 $(4,14)$. Na outra extremidade, as perguntas com média inferior a 2 foram: P28, P30, P21, P16 e P26. A partir desses resultados, subentende-se que, os servidores estão conscientes quanto ao uso do dinheiro, pagamento das dívidas e planejamento financeiro, esse entendimento se dar a partir de uma análise individual dos indicadores.

Entretanto, apesar de ter percebido uma consciência do servidor por meio das algumas perguntas individuais, nota-se, que nenhum dos constructos estruturado inicialmente, apresentou coerência interna significativa. Todos eles sucederam com um Alpha de Cronbach em níveis ruins (abaixo de 0,50 ) - Tabela 4.

Para o $1^{\circ}$ Constructo Atitude Financeira, não foi possível rodar a análise fatorial exploratória (AFE). Para o $2^{\circ}$ e $3^{\circ}$ Constructo foi realizado AFE, mas não se obteve êxito quanto aos agrupamentos findados, ou seja, não indo de encontro aos constructos propostos. Outro fator crítico foi referente à confiabilidade das perguntas frente aos $2^{\circ}$ e $3^{\circ}$ constructos, o indicador "Alpha cronbach". Os valores não incidiram em níveis aceitáveis $\left(2^{\circ}\right.$ constructo $=$ 0,46 e $3^{\circ}$ constructos $\left.=0,27\right)-$ Tabela 4 .

Tabela 4 - Estatística descritiva dos Indicadores

\begin{tabular}{|c|c|c|c|c|}
\hline Perguntas & Média & $\begin{array}{l}\text { Desvio } \\
\text { Padrão }\end{array}$ & $\begin{array}{l}\text { Constructos } \\
\text { Proposto }\end{array}$ & $\begin{array}{l}\text { Alpha de } \\
\text { Crobanch }\end{array}$ \\
\hline $\begin{array}{l}\text { P23 - Quando você decide comprar um produto à } \\
\text { prestação você consulta os seus gastos para ver se terá } \\
\text { condições para pagar todas as prestações. }\end{array}$ & 3,81 & 1,32 & \multirow{3}{*}{$\begin{array}{l}\text { Atitude } \\
\text { Financeira }\end{array}$} & \multirow{3}{*}{$-0,13$} \\
\hline $\begin{array}{l}\text { P28 - Você identifica um bem como sendo essencial para } \\
\text { você quando o mesmo lhe dá destaque entre os amigos e } \\
\text { conhecidos. }\end{array}$ & 1,69 & 1,13 & & \\
\hline $\begin{array}{l}\text { P30 - Você não precisa poupar, pois terá a aposentadoria } \\
\text { pelo Serraprev. }\end{array}$ & 1,49 & 0,87 & & \\
\hline $\begin{array}{l}\text { P12 - Ter Educação Financeira significa saber planejar } \\
\text { os gastos de acordo com a renda. }\end{array}$ & 4,16 & 0,95 & \multirow{9}{*}{$\begin{array}{l}\text { Comportamento } \\
\text { Financeiro }\end{array}$} & \multirow{9}{*}{0,46} \\
\hline $\begin{array}{l}\text { P13 - Você é uma pessoa com conhecimentos suficientes } \\
\text { para administrar sozinho suas finanças. }\end{array}$ & 3,92 & 0,95 & & \\
\hline $\begin{array}{l}\text { P18 - Quase metade do seu salário está comprometido } \\
\text { com financiamentos. }\end{array}$ & 2,27 & 1,38 & & \\
\hline $\begin{array}{l}\text { P19 - Você planeja seus financiamentos. Só adquire } \\
\text { novo financiamento quando quita o anterior. }\end{array}$ & 3,46 & 1,35 & & \\
\hline P20 - Você somente recorre a empréstimos, consignados & & & & \\
\hline $\begin{array}{l}\text { ou financiamentos somente para gastos urgentes ou } \\
\text { diante de algum imprevisto. }\end{array}$ & 3,73 & 1,31 & & \\
\hline $\begin{array}{l}\text { P21 - A sua dívida que consome a maior parte do seu } \\
\text { salário é a do financiamento da sua casa. }\end{array}$ & 1,95 & 1,38 & & \\
\hline $\begin{array}{l}\text { P24 - Você sempre paga as prestações dos seus } \\
\text { empréstimos em dia. }\end{array}$ & 3,89 & 1,21 & & \\
\hline P27 - Poupar significa segurança para o futuro. & 4,33 & 0,92 & & \\
\hline P10 - Você planeja seus gastos a partir do seu salário. & 4,19 & 1,00 & \multirow{4}{*}{$\begin{array}{l}\text { Conhecimento } \\
\text { Financeiro }\end{array}$} & \multirow{4}{*}{0,27} \\
\hline $\begin{array}{l}\text { P11 - Você conhece o significado de educação } \\
\text { financeira. }\end{array}$ & 3,88 & 1,02 & & \\
\hline P14 - Taxa de juros é o preço do dinheiro. & 3,33 & 1,25 & & \\
\hline P15 - Você é capaz de identificar a taxa de juros cobrada & 3,36 & 1,28 & & \\
\hline
\end{tabular}


em um financiamento.

P16 - Quando uma pessoa adquire um cartão de crédito é

como se a sua renda tivesse aumentado.

$1,72 \quad 1,27$

P17 - Você é uma pessoa que não tem dívidas.

$2,33 \quad 1,41$

P22 - Toda vez que você compra um produto a prazo,

você sabe que terá o dinheiro para pagar a prestação nos

meses seguinte nas datas de vencimento.

P25 - Você tem mais de uma fonte de renda. $\quad 3,21 \quad 1,65$

P26 - Cartão de crédito é como um segundo salário. $\quad 1,46 \quad 0,92$

P29 - Quando você fala "minhas finanças" significa que $\quad 2,66 \quad 1,41$

está falando somente do seu salário.

Fonte: Dados da pesquisa. Elaborado pelo autor.

Como o Alpha de Crobanch não permitiu confirmar as variáveis (construtos) recomendadas, foi aplicada então, a Análise Fatorial Exploratória (AFE) para que se pudesse identificar uma nova estrutura (fatores) que representassem a educação financeira dos servidores, aplicada na estrutura de indicadores.

\subsection{ANÁLISE FATORIAL}

Em termos gerais, a análise fatorial trabalha com o problema de analisar a estrutura das correlações entre um grande número de variáveis (itens de testes, respostas de questionários e etc.), definindo um conjunto de dimensões latentes comuns, chamadas de fatores (HAIR et al., 2005). Ao contrário da seção 4.1, nesta segunda etapa da pesquisa, foram explorados os conjuntos de respostas das perguntas da Tabela 4, tendo como foco elaborar uma nova estrutura latente que explicasse os perfis dos servidores quanto à educação financeira, tendo em vista, que estrutura inicial não apresentou estatística em níveis, no ponto de vista teórico, aceitáveis.

Portanto, no primeiro momento, avaliou-se a correlação entre os indicadores (perguntas), em seguida o teste de "esferidade de Bartlett's" e o teste "Kaiser-Meyer-Olkin (KMO)", e derivando por fim o modelo fatorial.

\subsection{MATRIZ DE CORRELAÇÃO DOS INDICADORES}

De acordo com Levine (2014, p. 117), “o coeficiente de correlação mede a força relativa de uma relação linear entre duas variáveis numéricas". Se $\rho=1$ significa correlação positiva perfeita, se $\rho=-1$ significa correlação negativa perfeita e $\rho=0$ não há correlação entres as variáveis.

A Tabela 5 exibe a matriz de intercorrelações amostral entre os indicadores, onde se destaca de "CINZA" as correlações significativas ao nível de $1 \%$ ou 5\%. 
De acordo com cálculo da matriz de correlação (Tabela 5), nota-se que grande número de correlações significativas, de um total de 211 correlações estimadas, 110 incidiram como significativa (52\%). Por exemplo, a pergunta P11 se mostrou significativa com as perguntas P12 e P13, ou seja, se o servidor conhece o significado de educação financeira, ele saberá planejar os gastos de acordo com a renda, e também que ele possui conhecimentos suficiente para administrar suas finanças. Outro ponto importante referente às perguntas citadas seria que, na estrutura proposta na subseção 1.2, P12 e P13 ficaram enquadradas no constructo "Comportamento Financeiro" e P11 como "Conhecimento Financeiro", essa evidenciação vem para apoia à ideia do autor de propor uma nova estrutura de constructo latente. 
Tabela 5 - Matriz de Correlação dos Indicadores (Perguntas)

\begin{tabular}{|c|c|c|c|c|c|c|c|c|c|c|c|c|c|c|c|c|c|c|c|c|c|}
\hline & P10 & P11 & P12 & P13 & P14 & P15 & P16 & P17 & P18 & P19 & P20 & P21 & P22 & P23 & P24 & P25 & P26 & P27 & P28 & P29 & P30 \\
\hline P10 & 1,00 & & & & & & & & & & & & & & & & & & & & \\
\hline P11 & 0,06 & 1,00 & & & & & & & & & & & & & & & & & & & \\
\hline P12 & $0,09 * *$ & $0,39 * *$ & 1,00 & & & & & & & & & & & & & & & & & & \\
\hline P13 & 0,05 & $0,34 * *$ & $0,40 * *$ & 1,00 & & & & & & & & & & & & & & & & & \\
\hline P14 & 0,07 & $0,14 * *$ & $0,11 * *$ & $0,44 * *$ & 1,00 & & & & & & & & & & & & & & & & \\
\hline P15 & 0,03 & $0,22 * *$ & $0,08^{*}$ & $0,41 * *$ & $0,45 * *$ & 1,00 & & & & & & & & & & & & & & & \\
\hline P16 & $-0,10 * *$ & $-0,08^{*}$ & 0,00 & $-0,07$ & 0,02 & $-0,23 * *$ & 1,00 & & & & & & & & & & & & & & \\
\hline P17 & $-0,09 * *$ & 0,07 & $0,07 *$ & $0,07 *$ & 0,02 & $-0,05$ & $0,31 * *$ & 1,00 & & & & & & & & & & & & & \\
\hline P18 & $-0,12 * *$ & 0,05 & $-0,04$ & 0,06 & $0,13 * *$ & 0,07 & $0,26^{* *}$ & $0,68 * *$ & 1,00 & & & & & & & & & & & & \\
\hline P19 & $-0,10 * *$ & $0,18 * *$ & $-0,04$ & $0,13 * *$ & $0,12 * *$ & $0,20 * *$ & 0,03 & 0,04 & $0,24 * *$ & 1,00 & & & & & & & & & & & \\
\hline P20 & 0,06 & $0,17 * *$ & $0,17 * *$ & $0,26 * *$ & $0,21 * *$ & $0,16 * *$ & 0,05 & $0,08 *$ & $0,13 * *$ & $0,41 * *$ & 1,00 & & & & & & & & & & \\
\hline P21 & $-0,05$ & $-0,11 * *$ & 0,02 & $-0,10 * *$ & $-0,17 * *$ & $-0,17 * *$ & $0,17 * *$ & $0,21 * *$ & $0,22 * *$ & 0,00 & $-0,09 * *$ & 1,00 & & & & & & & & & \\
\hline P22 & $-0,02$ & 0,04 & 0,06 & $0,20 * *$ & $0,074 *$ & $0,13 * *$ & $-0,04$ & $-0,05$ & $-0,02$ & $0,20 * *$ & $0,16 * *$ & $-0,02$ & 1,00 & & & & & & & & \\
\hline P23 & 0,00 & $0,10 * *$ & 0,06 & $0,17 * *$ & $0,11 * *$ & $0,10 * *$ & $-0,06$ & 0,01 & $-0,02$ & $0,11 * *$ & $0,16 * *$ & $-0,06$ & $0,27 * *$ & 1,00 & & & & & & & \\
\hline P24 & 0,03 & $0,15 * *$ & $0,1 * *$ & $0,20 * *$ & $0,08 *$ & $0,17 * *$ & $-0,09^{*}$ & 0,01 & $-0,01$ & $0,09 *$ & $0,16 * *$ & $-0,07 *$ & $0,26 * *$ & $0,28 * *$ & 1,00 & & & & & & \\
\hline P25 & 0,06 & 0,00 & 0,01 & 0,03 & $0,24 * *$ & $0,09 *$ & 0,06 & 0,01 & $0,10 * *$ & 0,00 & $0,08 *$ & $-0,08 *$ & 0,07 & 0,03 & $0,32 * *$ & 1,00 & & & & & \\
\hline P26 & $-0,05$ & $-0,09 * *$ & $-0,11 * *$ & $-0,17 * *$ & $-0,04$ & $-0,08 *$ & 0,06 & 0,02 & $0,08^{*}$ & $-0,04$ & $-0,01$ & 0,02 & $-0,05$ & $-0,08^{*}$ & $-0,07$ & $0,15 * *$ & 1,00 & & & & \\
\hline P27 & 0,01 & 0,07 & $0,15 * *$ & $0,20 * *$ & $0,13 * *$ & $0,12 * *$ & $-0,05$ & $-0,05$ & $-0,07^{*}$ & 0,05 & $0,08^{*}$ & $-0,07$ & $0,11 * *$ & $0,12 * *$ & $0,31 * *$ & $0,26 * *$ & $-0,08^{*}$ & 1,00 & & & \\
\hline P28 & 0,05 & $-0,06$ & $-0,10 * *$ & $-0,13 * *$ & $-0,05$ & $-0,07$ & 0,04 & $-0,02$ & 0,03 & $-0,10 * *$ & $-0,17 * *$ & 0,05 & $-0,10 * *$ & $-0,08 *$ & $-0,26 * *$ & $-0,26 * *$ & 0,01 & $-0,33 * *$ & 1,00 & & \\
\hline P29 & $-0,05$ & $-0,02$ & $-0,06$ & $-0,08^{*}$ & 0,01 & 0,02 & $0,08^{*}$ & 0,01 & 0,05 & 0,03 & $-0,01$ & 0,05 & 0,01 & $-0,07^{*}$ & $-0,08^{*}$ & $-0,04$ & 0,05 & $-0,08^{*}$ & 0,03 & 1,00 & \\
\hline P30 & 0,02 & 0,01 & $-0,09 *$ & $-0,09 * *$ & $-0,01$ & 0,01 & 0,01 & $-0,05$ & 0,01 & $-0,04$ & $-0,14 * *$ & $-0,08^{*}$ & $-0,07 *$ & $-0,08 *$ & $-0,07$ & 0,04 & $0,16^{* *}$ & $-0,11 * *$ & 0,04 & 0,03 & 1,00 \\
\hline
\end{tabular}

Nota: ** Correlação significativa ao nível de $1 \%$ e * Correlação significativa ao nível de $5 \%$.

Fonte: Dados da pesquisa. Elaborado pelo autor. 


\subsection{TESTES ESFERICIDADE DE BARTLETT E TESTE KAISER-MEYER-OLKIN (KMO)}

O teste de Bartlett's testa a presença de correlações entre os indicadores (perguntas). O teste Kaiser-Meyer-Olkin (KMO) fornece uma medida para quantificar o grau de intercorrelações entre os indicadores - índice que varia de zero a um. Através deles conseguese identificar quando cada indicador é perfeitamente previsto, sem erros, pelos outros (HAIR et al., 2005).

Tabela 6 - Resultado do teste de KMO e esfericidade de Bartlett's.

\begin{tabular}{lr} 
Kaiser-Meyer-Olkin & 0,67 \\
Bartlett's Qui-quadrado & 2822,99 \\
gl & 210 \\
p-valor & 0,00 \\
\hline
\end{tabular}

Fonte: Dados da pesquisa. Elaborado pelo autor.

Analisou-se a Tabela 6, em relação ao primeiro teste, verificou-se um p-valor (significância) de 0,00. Ou seja, indicando a presença de correlações entre as variáveis. E em relação ao segundo teste, a estatística KMO estimou um valor de 0,67 , referido por Hair et al. (2005) como "medíocre", mais aceitável. Deste modo, essas medidas sugeriram que o conjunto de indicadores (matriz de correlação) é adequado para uso da análise fatorial.

\subsection{RESULTADO DO MODELO FATORIAL}

$\mathrm{Na}$ análise fatorial conduzida para os indicadores foi realizada em um único momento para todas as perguntas. $\mathrm{Na}$ análise foram extraídos seis fatores responsáveis por $52 \%$ da variância total. Conforme a Tabela 7.

Pode-se observar por meio da Tabela 7 que das 20 perguntas que avaliam a Educação Financeira, 18 foram agrupadas em seis fatores. A pergunta P10 - "Você planeja seus gastos a partir do seu salário" - não se agrupou em nenhum fator e a pergunta P28 -"Você identifica um bem como sendo essencial para você quando o mesmo lhe dá destaque entre os amigos e conhecidos" - foi excluída da análise por decisão do autor, após simulação prévia do modelo.

Nos seis fatores formados, pode-se observar que todos os indicadores possuem cargas fatoriais adequadas (valores superiores a 0,30). Como orienta Hair et al. (2005), cargas superiores a 0,40 são suficientes com base em uma amostra de 200 respondentes, no presente estudo são 800 respondentes. 
Tabela 7 - Agrupamento dos índices em fatores

\begin{tabular}{|c|c|c|c|c|c|c|}
\hline \multirow{2}{*}{ Perguntas } & \multicolumn{6}{|c|}{ Fator } \\
\hline & 1 & 2 & 3 & 4 & 5 & 6 \\
\hline $\begin{array}{l}\text { P16 - Quando uma pessoa adquire um cartão de crédito é como se a } \\
\text { sua renda tivesse aumentado. }\end{array}$ & 0,59 & & & & & \\
\hline P17 - Você é uma pessoa que não tem dívidas. & 0,84 & & & & & \\
\hline $\begin{array}{l}\text { P18 - Quase metade do seu salário está comprometido com } \\
\text { financiamentos. }\end{array}$ & 0,82 & & & & & \\
\hline $\begin{array}{l}\text { P21 - A sua dívida que consome a maior parte do seu salário é a do } \\
\text { financiamento da sua casa. }\end{array}$ & 0,45 & & & & & \\
\hline $\begin{array}{l}\text { P13 - Você é uma pessoa com conhecimentos suficientes para } \\
\text { administrar sozinho suas finanças. }\end{array}$ & & 0,56 & & & & \\
\hline P14 - Taxa de juros é o preço do dinheiro. & & 0,80 & & & & \\
\hline $\begin{array}{l}\text { P15 - Você é capaz de identificar a taxa de juros cobrada em um } \\
\text { financiamento. }\end{array}$ & & 0,79 & & & & \\
\hline $\begin{array}{l}\text { P19 - Você planeja seus financiamentos. Só adquire novo } \\
\text { financiamento quando quita o anterior. }\end{array}$ & & & 0,71 & & & \\
\hline $\begin{array}{l}\text { P20 - Você somente recorre a empréstimos, consignados ou } \\
\text { financiamentos somente para gastos urgentes ou diante de algum } \\
\text { imprevisto. }\end{array}$ & & & 0,64 & & & \\
\hline $\begin{array}{l}\text { P22 - Toda vez que você compra um produto a prazo, você sabe que } \\
\text { terá o dinheiro para pagar a prestação nos meses seguinte nas datas } \\
\text { de vencimento. }\end{array}$ & & & 0,61 & & & \\
\hline $\begin{array}{l}\text { P23 - Quando você decide comprar um produto à prestação você } \\
\text { consulta os seus gastos para ver se terá condições para pagar todas as } \\
\text { prestações. }\end{array}$ & & & 0,50 & & & \\
\hline P24 - Você sempre paga as prestações dos seus empréstimos em dia. & & & & 0,66 & & \\
\hline P25 - Você tem mais de uma fonte de renda. & & & & 0,69 & & \\
\hline P27 - Poupar significa segurança para o futuro. & & & & 0,67 & & \\
\hline P11 - Você conhece o significado de educação financeira. & & & & & 0,72 & \\
\hline $\begin{array}{l}\text { P12 - Ter Educação Financeira significa saber planejar os gastos de } \\
\text { acordo com a renda. }\end{array}$ & & & & & 0,80 & \\
\hline P26 - Cartão de crédito é como um segundo salário. & & & & & & 0,70 \\
\hline $\begin{array}{l}\text { P30 - Você não precisa poupar, pois terá a aposentadoria pelo } \\
\text { Serraprev. }\end{array}$ & & & & & & 0,63 \\
\hline \% Variância Explicada & $10 \%$ & $10 \%$ & $9 \%$ & $8 \%$ & $8 \%$ & $7 \%$ \\
\hline \% Variância Acumulada & $10 \%$ & $20 \%$ & $29 \%$ & $37 \%$ & $46 \%$ & $52 \%$ \\
\hline
\end{tabular}

Fonte: Dados da pesquisa. Elaborado pelo autor.

Definidos fatores e seus respectivos indicadores, novamente avaliou a confiabilidade interna por meio Alpha de Cronbach, mas agora para novos constructos formados - Quadro 2. Os valores do Alpha foram de 0,52 a 0,64 para cinco fatores, sendo que, apenas em um, o valor estimado se mostrou bem abaixo do nível recomendado.

\begin{tabular}{|l|l|c|l|}
\hline \multicolumn{1}{|c|}{ Constructos } & \multicolumn{1}{|c|}{ Perguntas } & \multicolumn{1}{c|}{$\begin{array}{c}\text { Alpha de } \\
\text { Crobanch }\end{array}$} & \multicolumn{1}{c|}{ Classificação } \\
\hline Conhecimento sobre o Endividamento & $16-17-18-21$ & 0,64 & Quanto menor melhor \\
\hline Conhecimento de Juros & $13-14-15$ & 0,69 & Quanto maior melhor \\
\hline Planejamento Financeiro & $19-20-22-23$ & 0,52 & Quanto maior melhor \\
\hline Nível de Empréstimos & $24-25-27$ & 0,54 & Quanto maior melhor \\
\hline Nível de Educação Financeira & $11-12$ & 0,55 & Quanto maior melhor \\
\hline Conhecimento da renda & $26-30$ & 0,28 & Quanto menor melhor \\
\hline
\end{tabular}

Quadro 2. Denominação, confiabilidade e classificação dos novos constructos

Fonte: Elaborado pelo autor. 
Frente a estes resultados, que a priori já demonstraram possuir níveis de qualidades adequadas à sua utilização como instrumento para avaliar a educação financeira, foi possível formar seis constructos, que representam 19 indicadores, com as respectivas denominações: constructo 1: Conhecimento Sobre Endividamento; Constructo 2: Conhecimento de Juros; Constructos 3: Planejamento Financeiro; Constructo 4: Nível de Empréstimos; Constructo 5: Nível de Educação Financeira; constructo 6: Conhecimento da renda.

\subsection{ESTATÍSTICA DESCRITIVA DOS FATORES}

A Tabela 8 apresenta a estatística descritiva dos constructos construídos decorridos da análise fatorial. No que diz respeito ao "Conhecimento Sobre o Endividamento", 50\% dos respondentes discordo totalmente ou discordo (Mediana $=2,00$ ); ao avaliar o Conhecimento da renda, a média incidiu em 1,47, sendo que para 50\% responderam que discorda totalmente, ou seja, subentende-se que eles não consideram o cartão de crédito como segundo salário e/ou é necessário poupar, caso se aposentem no futuro.

Tabela 8 - Estatísticas descritivas dos Constructos

\begin{tabular}{lccccc}
\hline Constructos & Média & $\begin{array}{r}\text { Desvio } \\
\text { Padrão }\end{array}$ & Mínimo & Mediana & Máximo \\
\hline Conhecimento sobre o Endividamento & 2,07 & 0,94 & 1,00 & 2,00 & 5,00 \\
Conhecimento de Juros & 3,54 & 0,92 & 1,00 & 4,00 & 5,00 \\
Planejamento Financeiro & 3,78 & 0,80 & 1,25 & 4,00 & 5,00 \\
Nível de Empréstimos & 3,81 & 0,93 & 1,33 & 3,67 & 5,00 \\
Nível de Educação Financeira & 4,02 & 0,82 & 1,00 & 4,00 & 5,00 \\
Conhecimento da renda & 1,47 & 0,68 & 1,00 & 1,00 & 4,50 \\
\hline
\end{tabular}

Fonte: Dados da pesquisa. Elaborado pelo autor.

Notou-se também, por meio da Tabela 8 , que $50 \%$ dos servidores, consideram que possui Nível de Educação Financeira ou são Planejados Financeiramente ou possui Conhecimento de Juros.

$\mathrm{Na}$ Tabela 9, foi possível verificar a correlação entre os constructos. Por exemplo, o conhecimento de juros está positivamente correlacionado com planejamento financeiro, nível de empréstimo e educação financeira, ou seja, se o servidor possui conhecimento de juros, ele saberá planejar suas contas; ou paga seus empréstimos em dia; e ou possui educação financeira. 


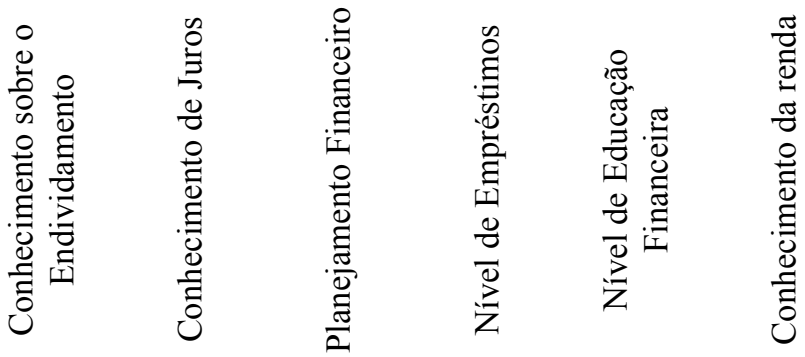

\begin{tabular}{lllllll}
\hline Conhecimento sobre o Endividamento & 1,00 & & & & & \\
Conhecimento de Juros & $-0,07$ & 1,00 & & & \\
Planejamento Financeiro & 0,04 & $0,30^{* *}$ & 1,00 & & \\
Nível de Empréstimos & $-0,03$ & $0,23^{* *}$ & $0,21^{* *}$ & 1,00 & \\
Nível de Educação Financeira & 0,00 & $0,31^{* *}$ & $0,16^{* *}$ & $0,18^{* *}$ & 1,00 \\
Conhecimento da renda & 0,02 & $-0,10^{* *}$ & $-0,13^{* *}$ & 0,00 & $-0,11^{* *}$ & 1,00 \\
\hline Nota: ** Correlação significativa ao nível de 1\% e * Correlação significativa ao nível de 5\%. \\
Fonte: Dados da pesquisa. Elaborado pelo autor.
\end{tabular}

Em contrapartida, se o servidor tem conhecimento de renda próximo de 5 (classificação: quanto menor melhor), notoriamente ele não possui conhecimento de juros; e/ou não sabe planejar suas finanças; e/ou não possui educação financeira satisfatória.

Sendo assim, após reduzido a dimensão dos indicadores de dezenove para seis constructos - explicou-se $52 \%$ da variância total, demonstrou a estatística descritiva das novas variáveis estabelecidas e a relevância frente a população de interesse, para responder a problemática da presente pesquisa, será aplicado a análise de agrupamento, utilizando os novos constructos, com objetivo de segmentar os servidores em grupos, que possibilitará caracterizar os perfis dos servidores em função desse grupos, juntamente com os construtos propostos.

\subsection{ANÁLISE DE AGRUPAMENTO}

O modelo de agrupamento teve como objetivo básico, nesta pesquisa, identificar o comportamento dos constructos de cada servidor, e posteriormente, agrupa-los em grupos, na buscar por padrões semelhantes. Os agrupamentos resultantes dos servidores devem então exibir homogeneidade interna e elevada heterogeneidade externa entre os grupos (HAIR et al., 2005).

Seguindo a recomendação do Hair et al. (2005, p. 402), neste estudo, optou-se por aplicar o método hierárquico de Ward e centroide para identificação do número de grupos. E sem seguida, fazer a validação com uso do método não hierárquico K-means. 
A seguir, são apresentados os centroides (médias) dos constructos por grupo, seguido pela caracterização destes através das características sócias demográficas, e por fim, uma descrição dos perfis dos servidores modo resumido.

\subsection{CARACTERIZAÇÃO DOS SERVIDORES POR PERFIL - GRUPOS}

As Tabelas 10 e 11 apresentam os grupos de servidores derivados pelo método não hierárquico k-means, sendo que a primeira informa centroides (média) por constructos e a segunda, as características sócias demográficas relevantes por grupo.

Ao avaliar as médias por constructos entre os grupos, nota-se, por exemplo, que, o grupo 1 com média moderadamente alta, próximo de 4,00 para "Conhecimento sobre o Endividamento", ou seja, os servidores são considerados desconhecido sobre o endividamento quando comparados com servidores do grupo 2, 3 e 4 - quanto menor melhor. Percebeu-se também que grupo 1, possui razoável conhecimento de juros, atrás apenas do grupo 2 e 4; eles também são servidores que se planejam financeiramente; e têm um excelente conhecimento de renda - quanto menor melhor. Quanto às características sócias demográficas, dominaram as seguintes informações: $81 \%$ são mulheres; $70 \%$ dos servidores têm idade entre 18 a 39 anos; $58 \%$ dos servidores não possui o ensino superior; e 36\% deles não possui casa própria.

A caracterização do grupo 2 é dada seguinte modo: são servidores que possuem conhecimento sobre dívida $(1,75)$, de juros $(4,05)$, sabem se planejar financeiramente $(4,04)$, pagam seus empréstimos (4,62), têm conhecimento da renda (1,55 - quanto menor melhor) e têm educação financeira, os servidores que constituir esse grupo podem ser considerados pessoas que têm uma educação financeira estável. No tocante às características sócias demográficas, observa-se que: $40 \%$ dos servidores são homens; $64 \%$ casados; $66 \%$ possuem no mínimo o ensino superior e $78 \%$ ganham acima de $\mathrm{R} \$ 2.000,00$ reais; e por fim, $84 \%$ têm casa própria que quitada ou que financiada.

Tabela 10 - Média dos constructos por grupos

\begin{tabular}{|c|c|c|c|c|c|c|c|}
\hline \multirow{3}{*}{ Fatores } & \multicolumn{4}{|c|}{ Grupos de Servidores } & \multirow{2}{*}{ Total } & \multirow{2}{*}{\multicolumn{2}{|c|}{$\begin{array}{c}\text { Anova para um } \\
\text { Fator }\end{array}$}} \\
\hline & \multirow{2}{*}{$\frac{1}{\text { Média }}$} & \multirow{2}{*}{$\frac{2}{\text { Média }}$} & \multirow{2}{*}{$\begin{array}{c}3 \\
\text { Média }\end{array}$} & \multirow{2}{*}{$\begin{array}{c}4 \\
\text { Média }\end{array}$} & & & \\
\hline & & & & & Média & Valor F & p-valor \\
\hline Conhecimento sobre o Endividamento & 3,96 & 1,75 & 2,14 & 1,74 & 2,07 & 340,29 & 0,00 \\
\hline Conhecimento de Juros & 3,46 & 4,05 & 2,52 & 3,44 & 3,54 & 119,18 & 0,00 \\
\hline Planejamento Financeiro & 4,04 & 4,04 & 3,31 & 3,63 & 3,78 & 35,45 & 0,00 \\
\hline Nível de Empréstimos & 3,80 & 4,62 & 3,62 & 3,04 & 3,81 & 299,68 & 0,00 \\
\hline Nível de Educação Financeira & 4,18 & 4,34 & 2,62 & 4,23 & 4,02 & 292,78 & 0,00 \\
\hline Conhecimento da renda & 1,29 & 1,55 & 1,82 & 1,31 & 1,47 & 21,44 & 0,00 \\
\hline Total de Servidores por Grupo & 95 & 300 & 120 & 285 & 800 & & \\
\hline
\end{tabular}


Nota: ** Correlação significativa ao nível de $1 \%$

Fonte: Dados da pesquisa. Elaborado pelo autor.

Já os servidores do grupo 3, têm a menor média entre grupos quanto a conhecimento de juros, educação financeira e planejamento, ou seja, eles têm conhecimento sobre endividamento e renda, possuem o menor nível de educação financeira e têm dificuldade no planejamento financeiro. Quanto ao perfil sócio demográfico, destacam-se: $62 \%$ dos servidores têm idade superior a 39 anos; apenas 48\% são casados (as); 69\% recebem acima de $\mathrm{R} \$ 2.000,00$ reais; e $82 \%$ têm casa própria que quitada ou que financiada.

Tabela 11 - Distribuição de frequência das variáveis sócia demográfica por grupo.

\begin{tabular}{|c|c|c|c|c|c|}
\hline \multirow{2}{*}{ Variável } & \multirow{2}{*}{ Característica Observada } & \multicolumn{4}{|c|}{ Grupos } \\
\hline & & 1 & 2 & 3 & 4 \\
\hline Gênero & Feminino & $81 \%$ & $60 \%$ & $77 \%$ & $73 \%$ \\
\hline Faixa de Idade & 18 a 39 anos & $70 \%$ & $41 \%$ & $38 \%$ & $52 \%$ \\
\hline Estado Civil & Casado (a) & $53 \%$ & $64 \%$ & $48 \%$ & $51 \%$ \\
\hline Nível de Escolaridade & No mínimo Ensino Superior & $42 \%$ & $66 \%$ & $53 \%$ & $57 \%$ \\
\hline Renda Mensal & Até $\mathrm{R} \$ 2.000,00$ & $37 \%$ & $22 \%$ & $31 \%$ & $28 \%$ \\
\hline Você mora em: & Não possui casa própria & $36 \%$ & $16 \%$ & $18 \%$ & $25 \%$ \\
\hline $\begin{array}{l}\text { Quando você pensa em dinheiro } \\
\text { você pensa em: }\end{array}$ & Segurança ou Sobrevivência & $92 \%$ & $89 \%$ & $84 \%$ & $90 \%$ \\
\hline
\end{tabular}

Fonte: Dados da pesquisa. Elaborado pelo autor.

E por fim, o grupo 4, representado por servidores que são educados financeiramente, tem conhecimento sobre dívida e renda, mas demonstram dificuldade quanto ao nível de empréstimo. Nos quesitos demográficos, destaca-se para este grupo: $27 \%$ são homens; $72 \%$ recebem acima de R $\$ 2.000,00$ e 25\% não dos servidores não possui casa própria.

\subsection{CONCLUSÕES DA MODELAGEM}

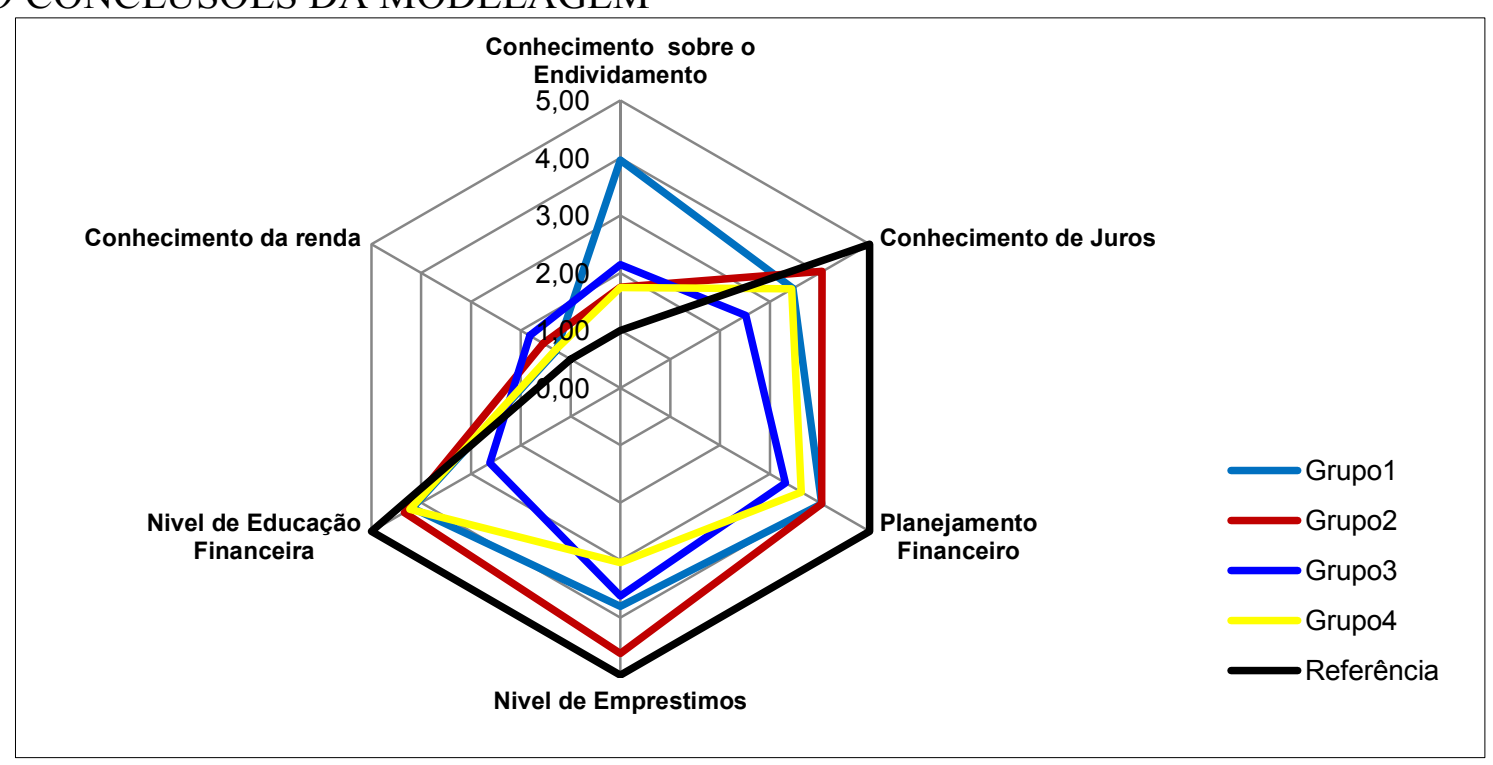

Figura 1 - Gráfico radar por constructos versos Grupos 
Fonte: Dados da pesquisa. Elaborado pelo autor.

No gráfico acima apresenta o que seria a relação perfeita dos constructos elaborados a parti do questionário, ou seja, o grupo ideal seria aquele com os valores para os constructos Nível de Endividamento valor: 1; Conhecimento sobre juros: 5; Planejamento financeiro: 5; Nível de Empréstimos: 5; Nível de Educação Financeira: 5; Conhecimento de Renda: 1.

Dentre os grupos constituídos pela pesquisa o grupo que melhor se aproxima do ideal é o grupo 2, que apresentam conhecimento juros, planejamento financeiro, nível de empréstimos e nível de educação financeira em média 4, e conhecimento sobre endividamento e conhecido de renda em média 1.

\section{CONCLUSÃO}

A pesquisa buscou elaborar o perfil dos servidores públicos municipais de Tangará da serra - MT perante o conceito de educação financeira e, também analisar o perfil financeiro destes servidores. Com os dados levantados através da pesquisa quantitativa, verificou-se que a maior parte dos servidores é do gênero feminino, correspondendo a $70 \%$, sendo do gênero masculino 30\%. Obteve-se que a média de idade entre os homens é de 38,6 anos, entre as mulheres é de 42,1 anos.

Constatou-se também que são, na sua grande maioria, casados, com famílias que não possuem de nenhum filho a 2 filhos e são residentes em casas próprias já quitadas.

Através do analise fatorial foi possível identificar os principais constructos que derivam do conceito de educação financeira e utilizando a técnica de agrupamento foi possível obter 4 grupos de servidores.

Sendo o grupo 1 que apresentam maior "Conhecimento sobre o Endividamento", ou seja, os servidores são considerados desconhecido sobre o endividamento, pois este constructo, quanto menor melhor. Conclui também que grupo 1, possui razoável conhecimento de juros, eles também são servidores que se planejam financeira; e têm um excelente conhecimento de renda - quanto menor melhor. Sendo composto este grupo: $81 \%$ são mulheres; $70 \%$ dos servidores têm idade entre 18 a 39 anos; $58 \%$ dos servidores não possui o ensino superior; e 36\% deles não possui casa própria.

A definição do grupo 2: são servidores que possui conhecimento sobre endividamento, de juros, sabem se planejar financeiramente, pagam seus empréstimos, apresentam conhecimento da renda e possuem educação financeira, os servidores que constituir esse grupo podem ser considerados pessoas que têm uma educação financeira estável. São: $40 \%$ dos servidores são homens; $64 \%$ casados; $66 \%$ possuem no mínimo o 
ensino superior e 78\% ganham acima de $\mathrm{R} \$ 2.000,00$ reais; e por fim, $84 \%$ têm casa própria que quitada ou que financiada.

O grupo 3, apresentou a menor média entre grupos quanto a conhecimento de juros, educação financeira e planejamento, ou seja, eles têm conhecimento sobre endividamento e renda, possui o menor nível de educação financeira e têm dificuldade no planejamento financeiro. Observou-se: $62 \%$ dos servidores têm idade superior a 39 anos; apenas $48 \%$ são casados (as); 69\% recebem acima de $\mathrm{R} \$ 2.000,00$ reais; e $82 \%$ têm casa própria que quitada ou que financiada.

O grupo 4, representou os servidores que são educados financeiramente, tem conhecimento sobre dívida e renda, mas demonstram dificuldade quanto ao nível de empréstimo. Ressaltou-se: $27 \%$ são homens; $72 \%$ recebem acima de R $\$ 2.000,00$ e 25\% não dos servidores não possui casa própria.

$\mathrm{Na}$ definição do perfil geral dos servidores relacionados a educação financeira, apresentam baixo conhecimento sobre o endividamento, em média, 2,07, e baixo conhecimento de renda, em média, 1,47, fato este bom, pois estes dois constructos, são analisados - quanto menor melhor. Apresentam um nível de educação financeira, satisfatório, em média, 4,23. Possuem conhecimento de juros, em média, 3,54, e planejam seus gastos, em média, 3,78, sendo estes constructos, analisados - quanto maior melhor.

Não foi possível analisar os hábitos de vida e consumos do grupo pesquisado para correlacionar sua preocupação com saúde e moradia. Os hábitos financeiros mais detalhados, como os principais gastos não foram identificados. A pesquisa apenas limitou-se a conhecer a renda do servidor diante do cargo efetivo e saber se os mesmos possuem mais de uma fonte de renda.

Sugere-se que novas pesquisas sejam desenvolvidas buscando conhecer os hábitos financeiros dos servidores públicos do município de Tangará da Serra - MT, visando explicar o consumo desse grupo específico, assim como relacionar a representativa desse consumo na economia local.

\section{REFERÊNCIAS}

BORGES, P.R.S. Educação Financeira: o novo perfil das famílias na administração das finanças pessoais. In: ENCONTRO DE PRODUÇÃO CIENTÍFICA E TECNOLÓGICA, 9., 2014, Campo Mourão/PR. Anais... Campo Mourão/PR, 2014. Disponível em: 
$<$ www.fecilcam.br/nupem/anais ix epct/PDF/TRABALHOS.../19.pdf $>$. Acesso em: 20 mar. 2016.

CERBASI, G. A complexa educação Financeira. Disponível em:

$<$ http://www.maisdinheiro.com.br/artigos $>$. Acesso em: 20 mar. 2016.

CLAUDINO, L. P. et al. Finanças pessoais: um estudo de caso com servidores públicos. In: SEMINÁRIO EM ADMINISTRAÇÃO, 12., 2009, São Paulo. Anais... São Paulo, 2009.

Disponível em: $<$ www.ead.fea.usp.br/semead/12semead/resultado/an_resumo.asp $>$. Acesso em: 16 fev. 2014.

DONADIO, R. Educação Financeira de estudantes universitários: uma análise dos fatores de influência. Tese (Doutorado) - UNINOVE, São Paulo, SP, 2014. Disponível em:

$<$ https://repositorio.uninove.br/xmlui/handle/123456789/685> $>$. Acesso em: 20 mar. 2016.

ENEF - Estratégia Nacional de Educação Financeira. Cadernos Educação Financeira.

Disponível em: http://www.vidaedinheiro.gov.br/pagina-29-

quem_somos_e_o que fazemos.html. Acesso em: 16 dez. 2015.

FERNANDES, A. H. S.; CANDIDO, J. G. Educação Financeira e nível do endividamento: relato de pesquisa entre os estudantes de uma instituição de ensino da cidade de São Paulo.

Revista eletrônica gestão e serviços, v.5, n. 2, p. 894-913, 2014. Disponível em:

$<$ https://www.metodista.br/revistas/revistas-ims/index.php/REGS/article/viewArticle/4868 $>$.

Acesso em: 16 fev. 2014.

FERRÃO, R. G. Metodologia cientifica para iniciantes em pesquisa. Unilinhares/Incaper, 2003.

FLORES, S. A. M.; VIEIRA, K. M. Influência de fatores comportamentais na propensão ao endividamento. Revista de Adm FACES Journal Belo Horizonte, v.12, n. 2, p. 13-35, 2013. Disponível em: < www.fumec.br/revistas/facesp/article/view/808 > . Acesso em: 15 fev. 2014.

FUNDOS DE INVESTIMENTOS. Cadernos CVM. Disponível em:

$<$ http://www.portaldoinvestidor.gov.br/menu/Menu Investidor/fundos investimentos/consult a portal.html > . Acesso em: 20 fev. 2014.

GIL, A. C. Métodos e técnicas de pesquisa social. 5. ed. São Paulo: Atlas, 1999.

GOMES, D. M.; SORATO, K. A. D. L. Planejamento e controle das finanças pessoais com enfoque na utilização das ferramentas contábeis: um estudo com profissionais autônomos.

Seminário de Ciências Sociais Aplicadas, v.2, n. 2, 2010. Disponível em:

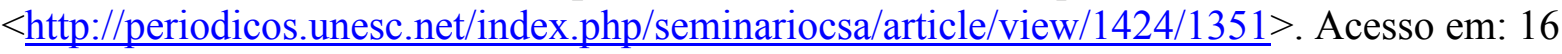
fev. 2014.

HAIR, J. F.; BLACK, W. C.; BABIN, B. J.; ANDERSON, R. E.; TATHAM, R. L. Análise Multivariada de Dados. 5.ed. Porto Alegre: Bookman, 2005.

HAIR, Jr.; JOSEPH F.; ANDERSON, R. E.; TATHAM, R. L.; BLACK, W.; HOJI, M. Administração financeira, uma abordagem prática. 3. ed. São Paulo: Atlas, 2007.

IBGE - Instituto Brasileiro de Geografia e Estatística. Dados populacionais. Disponível em: $<$ http://ibge.gov.br/cidadesat/painel/populacao.php?lang=\&codmun=510795\&search=matogrosso|tangara-da-serra|infograficos:-evolucao-populacional-e-piramide-etaria $>$. Acesso em: 09 jun. 2015. 
LEAL, C. P.; NASCIMENTO, J. A. R. Planejamento Financeiro Pessoal. Brasília, 2008. Disponível em: $<\underline{w w w}$.fasep.edu.br/prova/arquivo.phd?arquivo=artigo plan.pdf $>$. Acesso em: 14 fev. 2014.

LIKERT, R. Una Técnica para la Medicion de Atitudes. In: WEINERMAN, C. H. Escalas de Medicion en Ciências Sociales. Buenos Aires: Nueva Vision, p.201-260. 1976.

MACEDO JR. Jurandir. A árvore do dinheiro: guia para cultivar a sua independência financeira. Rio de Janeiro: Elsevier, 2007.

MATSUMOTO, A. S. et al. Finanças pessoais: um estudo sobre a importância do planejamento financeiro pessoal. In: ENCONTRO NACIONAL DOS CURSOS EM ADMINISTRAÇÃO, 24., 2013, Santa Catarina. Anais... Santa Catarina: ENAGRAD, 2013. MINISTÉRIO DA PREVIDÊNCIA. Quantidade funcionários públicos. Disponível em: $<\underline{\text { http://cadprev.previdencia.gov.br/Cadprev/faces/pages/modulos/dipr/consultarDemonstrativ }}$ os.xhtml>. Acesso em: 12 jun. 2015.

OLIVEIRA, R. B.; KASPCZAK, M. C. M. Planejamento Financeiro pessoal: uma revisão bibliográfica. Paraná, 2013. Disponível em:

<www.admpg.com.br/2013/down.php?id=577\&q=1 >. Acesso em: 13 fev. 2014.

PEREIRA, M. A. et al. Decision process based on personal finance books: is there any direction to take? Revista de Economia e Administração, v. 9, n. 3, 2010. Disponível em: <www.spell.org.br/documentos/download/5026>. Acesso em: 15 fev. 2014.

POTRICH, A. C. G.; VIEIRA, K. M.; KIRCH, G. Você é alfabetizado financeiramente? Descubra no termômetro de alfabetização financeira. In: ENCONTRO BRASILEIRO DE ECONOMIA E FINANÇAS COMPORTAMENTAIS, 01., 2014, São Paulo. Anais... São Paulo, 2014. Disponível em:

$<$ http://cef.fgv.br/sites/cef.fgv.br/files/[Mendes\%20et\%20al] $\% 20 \mathrm{VOCE} \% 20 \mathrm{E} \% 20 \mathrm{ALFABET}$ IZADO\%20FINANCEIRAMENTE.pdf>. Acesso em: mar 2016.

ROVER, S. et al. Efeito sunk costs: o conhecimento teórico influencia no processo decisório de discentes. Brazilian Business Review, v. 8, n. 3, p. 247-263, 2009.

SAITO, A. T. Uma contribuição ao desenvolvimento da educação em finanças pessoais no Brasil. Dissertação (Mestrado), São Paulo, SP, 2007. Disponível em:

$<$ http://www.teses.usp.br/teses/disponiveis/12/12139/tde-28012008-141149/pt-br.php $>$.

Acesso em: 15 fev. 2014.

SANTOS, J. O.; BARROS, C. A. S. O que determina a tomada de decisão financeira: razão ou emoção? RBGN - Revista Brasileira de Gestão de Negócios, v. 13, n. 38, p. 7-20, 2011.

SLOMP, J.Z.F. Endividamento e Consumo. Revista Relações de Consumo, 2008.

Disponível em: $<$ http://procon.caxias.rs.gov.br/site/_uploads/publicacoes/publicacao_4.pdf $>$. Acesso em: 13 jun. 2015.

VIEIRA, S.F.A.; BATAGLIA, R. T. M.; SEREIA, V.J. Educação financeira e decisões de consumo, investimento e poupança; uma análise dos alunos de uma universidade pública do norte do Paraná. Revista de Administração da UNIMEP, v.9, n.3, 2011. Disponível em: $<$ http://www.regen.com.br/ojs/index.php/regen/article/view/345>. Acesso em: 15 dez. 2015.

WORTHINGTON, A. C. Predicting financial literacy in Australia. Financial Services Review, v.15, p.58-79, 2006. 